\title{
Geomorphological and Land Use / Land Cover Studies of Dhubdhubi Basin: District Solapur, Maharashtra"
}

\author{
*Unhale P L. ${ }^{1}$, Kolekar R D ${ }^{1}$., Prabhakar. P. ${ }^{2}$ Mujawar. K. C ${ }^{2}$ \\ ${ }^{1 .}$ School of Earth Sciences Solapur University, Solapur. \\ ${ }^{2}$. Deptt. Of Civil Engineering, N.B. Navale Sinhgad College of Engineering, Kegaon, Solapur.
}

\begin{abstract}
A drainage basin is simply the area that gathers water from precipitation and delivers it to a larger stream, lake or ocean. It is an area limited by a drainage divide and occupies by a drainage network wherein the upstream drainage basin supplies water and sediment to the lower parts reflecting the upstream geologic and hydrologic character of watershed. In the present study the morphometric analysis is quantitatively done with (ARC GIS 10.0) and ERDAS which is a powerful tool and it is advanced very easily measuring basin length, basin, area, automatic creating of drainage network, stream order, stream length, circular area of basin etc. Fragments in the creation of basin, delineation of drainage network, stream length, flow direction and stream orders. Using Arc Gis technique the work of mapping, statistics, analysis, displaying the data and output is done. The Land Use and Land Cover map of the study area shows total area under study is $478.67 \mathrm{sqkm}$, contain total built up coverage at about $4.89342 \mathrm{sqkm}$. High concentration of settlement situated in Walsang and Karajgi which covers north\& West side of the study area. The water bodies that are present in the study area are Dindur Lake, Achegaon Lake and Shirpanhalli Lake which covers area 3.57606 sqkm (Hoston (1956) and strahler (1964).GIS study allows reliable most accurate and most updated database on land resources. It has also been very useful in deriving geo-morphometric parameters. In the present study GIS software are used to preparation of Base map, elevation map and base map of dhubdhubi basin.
\end{abstract}

Keyword: Dhubdhubi basin, watershed Morphometric analysis, LULC, GIS

\section{Introduction}

A drainage basin is simply the area that gathers water from precipitation and delivers it to a larger stream, lake or ocean. It is an area limited by a drainage divide and occupies by a drainage network wherein the upstream drainage basin supplies water and sediment to the lower parts reflecting the upstream geologic and hydrologic character of watershed.

The drainage basin is the response slope, bedrock, lithology and climate of that region which determines the characteristics of basin. Hence quantities analysis and them inter relationship are important to support decision for various themes. The methods of quantitative analysis of drainage basin was developed by Horton and modified by strahler in conventional means but recently geographic information system and satellite remote sensing is a complete tool to Analyse to update and to correlate the measurement with periodic changes. Therefore, the results are more realistic and the time consuming. This study is to evaluate the nature of the drainage basins and relationship with characters of the terrains and for deriving means to conserve and manage natural resources and combating natural hazards. The study is soused on linear aspects and LULC of the catchment area using geographic information system tools.Geographic information system (GIS) are and Remote sensing have prove to be efficient tools in delineation of drainage patterns and water resources planning. Geographic information systems (GIS) has been widely used in several geomorphologic, morphometric, flood management, and environmental application (eg .Dawod and Mohamed, 2009 , EI Bastawesy et al , 2010, Rao et al , 2010 , Dawod and Mahamed , 2008 and Dongquan et al , 2009 ) .

Evaluation of the morph metric parameters involves preparation of drainage networks maps ordering of the various streams, measurements of catchment area, perimeter, relative relief, and relief ratio, length of drainage channels, drainage density, drainage frequency, bifurcation ratio, texture ratio, circulatory ratio and constant channel maintainers which helps to understand the natures of the drainage properties of basin. Morphometric parameters could be used in many of the watershed for application like terrain analysis, delineations of geomorphological features, quantitative geomorphology, pedo-geomorphological studies, land degradation studies, watershed prioritization, calculating flow direction, calculating flow accumulation assessment of runoff and top soil loss, hydro geomorphology, estimate peaks runoff rate, delineation of groundwater potential zone, flood zone and mapping etc.

\section{Objectives}

- To determine different geomorphic and morphometric parameters of the basin.

- To find out inter relationship between various parameters. 
- $\quad$ To assess the watershed characteristics of the study area.

- To study drainage morphometry and its influence on hydrology.

- To study the Land Use / Land Cover pattern of the study area.

\section{Study Area}

The study area is in Maharashtra state. This technique has been attempted in the present investigations in the Dhubdhubi basin, it is in south Solapur \& Akkalkot taluka of Solapur district Maharashtra.It lies between latitude $17^{\circ} 21^{\prime}$ to $1741^{\prime} \mathrm{N}$ and longitude $76^{\circ} 00^{\prime}$ to $76^{\circ} 11^{\prime} \mathrm{E}$.

Figure 1 shows location map of the study area.

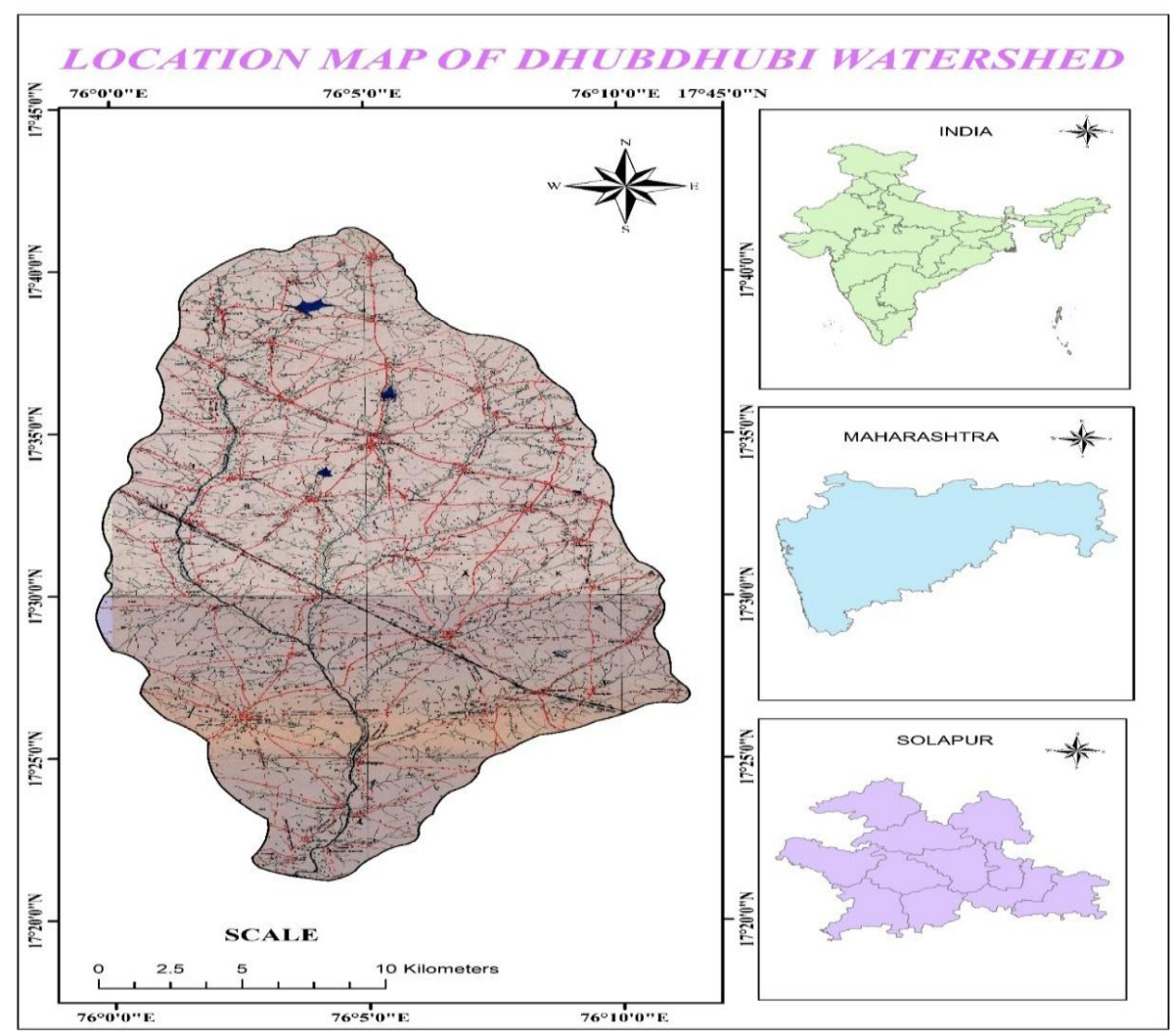

Fig: 1 Location map of the study area

\section{Geology of the study area}

From the accompanying map showing the regional geological setting, it will be seen that the area includes Deccan trap lava flows and they have assumed a great importance in Indian stratigraphy because of the great variety of rock types, complex structural features.

The study area shows the basaltic lava flows which represent the peripheral portions of the Deccan traps. They occupy the western, central and southern India. The Deccan traps are the most extensive geological formations of the Indian peninsula, ranging in age from upper cretaceous to Oligocene (Krishnan, 1968). The traps are divided into three main divisions, viz the upper, the middle and the lower with the inter -trapping beds at the base. They are generally composed of fine grained compact basalts which at places are vesicular and amygdaloidal, amygdales containing secondary minerals like zeolites and different from the silica.

\section{Methodology And Data Used}

Application of Geographical Information System (GIS) in Geomorphometry:

The morphometric analysis is quantitatively done is the (ARC GIS 10.0) and ERDAS which is a powerful tool and it is advanced very easily measuring basin length, basin, area, automatic creating of drainage network, stream order, stream length, circular area of basin etc. And in the creation of basin, delineation of drainage network, stream length, flow direction and stream orders. Using Arc Gis technique the work of mapping, statistics, analysis, displaying the data and output is done. In the process of morphometric analysis Arc Gis tools like analysis tools (AT), conversion tools (CT) data management tools (DMT), Geostatistical tools (GT) and spatial analysis tools(SAT) etc. are used. Using all the tools, morphometric analysis of Dhubdhubi Odha basin is carried out quantitatively using Arc Gis 10.0software. 
Geographic information system (GIS) is a special type of information system in which the database consists of observation on spatially distributed features and procedure to collect, stores, retrieve, analyse and display such geographic data. Geographic information system (GIS) links map features with database attributes. The integration of digital mapping and data base capabilities is what sets geographic information system (GIS) apart from other information system

\section{Data Preparation:}

\section{Methodology:}

The major goal of the study is to develop a viable methodology for producing geographic information system (GIS) data model for drainage morphometric analysis to discover holistic stream properties from the measurement of various stream attributes using Arc Gis software. The required necessary data sources for morphometric analysis were carried out through the use of survey of India (SOI) Toposheets of the area. The Toposheets were geometrically rectified and georeferenced by taking ground control points (GCPs) by using UTM projection and WGS 84 datum further, all the geocoded images were mosaic using Eardas imagine 2011 image processing software. After that digitization work has been carried out for entire analysis of the basin for morphometric analysis using Arc Gis 10.0 software.

\section{Data analysis in geographical Information System (GIS):}

The order was given to each stream by following Horton (1969) stream ordering technique. The parameters like the number and length of stream of each different orders, drainage area, basin perimeter and basin length were calculated using Arc Gis software (10.0). From the above parameters drainage density drainage frequency, shape, form factor, circulatory ratio, elongation ratio etc. we calculated. The methodology adopted for the compotation of morphometric parameters is given below. With the help of covers ion tools in the Arc tool box; the data is converted into raster to vector form. Coverage tools and personal geodatabase tools were used in the area to estimate stream length. Topology tool was used to edit he line errors like polygon, point and node of overlapping and gap for accuracy. With the help of data management tools projection and transformation was made by registering of raster image with satellite image and topographical map. After this process bifurcation ratio, form factor, elongation ratio, drainage density, drainage frequency, steam frequency and drainage texture were analysed. The drainage basin analysis was arried out quantitatively aspects wise such as linear aspects, aerial aspect and relief aspect. I the linear aspects, stream order stream length, bifurcation ratio, mean stream length, stream length ratio and mean stream length ratio were analysed. In aerial aspect Basin area, drainage density, drainage frequency, infiltration number, drainage texture, form factor ratio, elongation ratio, circulatory ratio was calculated. In relief aspects basin relief, relief ratio, dissection Index, channel gradient and basin slope were analysed. The method of calculation and the procedure involved in estimating each parameter is briefly descried.

\section{Data used:}

Toposheets:

The study area lies in the survey of India (SOI) toposheet no $47 \mathrm{O} / 14,47 \mathrm{O} / 15,56 \mathrm{C} / 2,56 \mathrm{C} / 3$.

Morphometric analysis: According to Clarke (1966), morphometry is the measurement and mathematical analysis of the configuration of the earth surface, shape and dimension of its landform. The morphometric analysis is carried out through measurement of linear, aerial and relief aspects of the basin and slope contribution.

\section{Linear Aspects:}

Linear aspects of basin are related to the channel pattern of drainage network where in topological characteristics of stream segment are analysis. The drainage network which consist of all the segments of stream of a particular river, is reduced to the level of graphs, where stream junction acts a points (junction) become links or lines where in the number of all segment are counted their hierarchical order are determined, the length of all steam segments area measured and their different inter relationship are studied.(fig no2) Linear aspects include the measurement of linear features of drainage such as stream order, Mean stream length, stream length ratio, bifurcation ratio, meanbifurcation ratio, stream length, length of overland flow, basin parameter, basin length.(table no-1)

\section{Stream order:}

The first step in drainage basin analysis is designation of stream orders, following a system introduced into the United State by Hoston (1956) and slightly modified by strahler (1964) assuming that one has available drainage network map including all intermittent and permanent flow lines located in clearly defined villages, the 
smallest fingertip tributaries are designated as order 1 . Where two first order channels join, a channel segments of order 2 is found and so forth. After the drainage network elements have been assigned their order numbers the segment of each order are counted to yield the number $\mathrm{Nu}$ of segments of the given order $\mathrm{u}$. Thestream order is a measures of the degree of stream branching with in a basin. Earth length of stream s indicated by its order.

\section{Stream number:}

The count of stream channel in its order is known as stream number. The number of stream segments decreases as the order increases. The higher amount stream order indicate lesser permeability and infiltration Stream number is directly proportional to sie of contributing watershed to cannel dimensions. It is obvious that the number of stream of any given order will be fewer than for the net lower order but more numerous than for the next higher order. The number of stream decreases as the stream order increases. The stream number shows stream number usually decreased in geometric progression as the stream order increase. In the present study the order wise stream numbers estimated are given in the (table no 1.)

\section{Stream lengths:}

Mean stream length (Lsm) of a stream channel segments of order $\mathrm{u}$ is a dimensional property revealing the characteristics size of components of a drainage network and its contributing basin surfaces. Channel length is measured with the help of Arc GIS software directly from the stream order map. To obtain the mean stream length of channel (Lsm) of order $\mathrm{u}$, the total length is divided by the number of streams segment $\mathrm{Nu}$ of that order; thus. (Fig no-4)

$\mathrm{Lsm}=\mathrm{Lu} / \mathrm{Nu}$

Where, $\mathrm{Lu}=$ Total stream length of all orders

$\mathrm{Nu}=$ Total number of stream of all orders

The mean stream length is presented in table. It is seen that Lsm value exhibits variation from 0.70 to 15.33 . It is observed that Lsm values of Dhubdhubi Odha basin indicate that Lsm of the given order is greater than that of the lower order stream length shows linear graph when plotted against stream order which shows stream number usually decreases in geometric progression as the stream order increases.

\section{Mean Stream Length:}

According to Strahler (1964), the mean stream length is a characteristics property related to the drainage network and its associated surface. The mean stream length (Lsm) has been calculated by dividing the total stream length of order ' $u$ ' and number of stream of segment of order ' $u$ '.

It is calculated by the formula

Mean Stream Length $(\mathrm{Lsm})=\mathrm{Lu} / \mathrm{Nu}$

Where, $\mathrm{Lu}=$ Total stream length of Order ' $u$ '.

$\mathrm{Nu}=$ Total no. of stream segment of order ' $u$ '.

\section{Stream length ratio:}

Stream length ratio is defined as the average length of stream of any order to the average length of stream of the next lower order and it is expressed as

$\mathrm{Rr}=\mathrm{Lu} / \mathrm{Lu}-1$

Where $\mathrm{Lu}=$ Total stream length of all orders

Lu-1= Total stream length of its next order.

The length ratio in the basin area is ranging from 1.52 to 2.65 .

\section{Bifurcation ratio:}

The bifurcation ratio $(\mathrm{Rb})$ is defined as the ratio of number of the stream segments of given order to the number of segments of the next higher order (scheme, 1956)It is calculated by $\mathrm{Rb}=\mathrm{Nu} / \mathrm{Nu}+1$

Where $\mathrm{Rb}=$ Bifurcation ratio

$\mathrm{Nu}=$ Total number of streams of all order

$\mathrm{Nu}+1=$ Number of segment of next higher order.

Strahler (1957) demonstrated that bifurcation ratio shows a small range of variation for different regions or for different environment except where the power full geological control dominates. Bifurcation ratios characteristically ranges between 2.33 to 5.57 for watersheds in with the geologic structure do not distort the drainage pattern (Strahler 1964). Bifurcation ratio is mainly controlled by the basin shape and is not only influence the landscape and morphometry but also control the surface runoff. 


\section{Mean Bifurcation Ratio:}

The mean bifurcation ratio may be defined as the average of bifurcation ratio of all orders and all sub watershed fall under normal basin category (Strahler, 1957).

Mean bifurcation Ratio $(\mathrm{Rbm})=$ Average of bifurcation ratio of all order.

\section{Length of overland flow:}

The length of overland flow defined as "the mean horizontal length of flow path from the divide to the stream in a first order basin and is measure of stream spacing and degree of dissection and is approximately one half te reciprocal of drainage density. It is one of the most important morphometric variable which affect the hydrological and topographical development of basin.

It is calculated by the formula. $\mathrm{Lg}=1 / 2 \mathrm{DWhere} \mathrm{D}=$ Drainage density

Table no:1 shows Basin area and Stream order of Dubdhubi basin

\begin{tabular}{|l|l|l|l|l|}
\hline River Basin & $\begin{array}{c}\text { Basin Area } \\
(\mathrm{A}) \\
\mathrm{Sq} . \mathrm{Km}\end{array}$ & $\begin{array}{c}\text { Stream Orders } \\
(\mathrm{u})\end{array}$ & $\begin{array}{c}\text { Number of Streams } \\
(\mathrm{Nu})\end{array}$ & $\begin{array}{c}\text { Total length of Streams } \\
\text { in } \mathrm{km} \\
(\mathrm{Lu})\end{array}$ \\
\hline Dhubdhubi Basin & 478.67 & 1 & 803 & 567013 \\
\hline & & 2 & 200 & 213.68 \\
\hline & 3 & 39 & 82.87 \\
\hline & & 4 & 3 & 39.60 \\
\hline & 5 & 3 & 26.02 \\
\hline
\end{tabular}

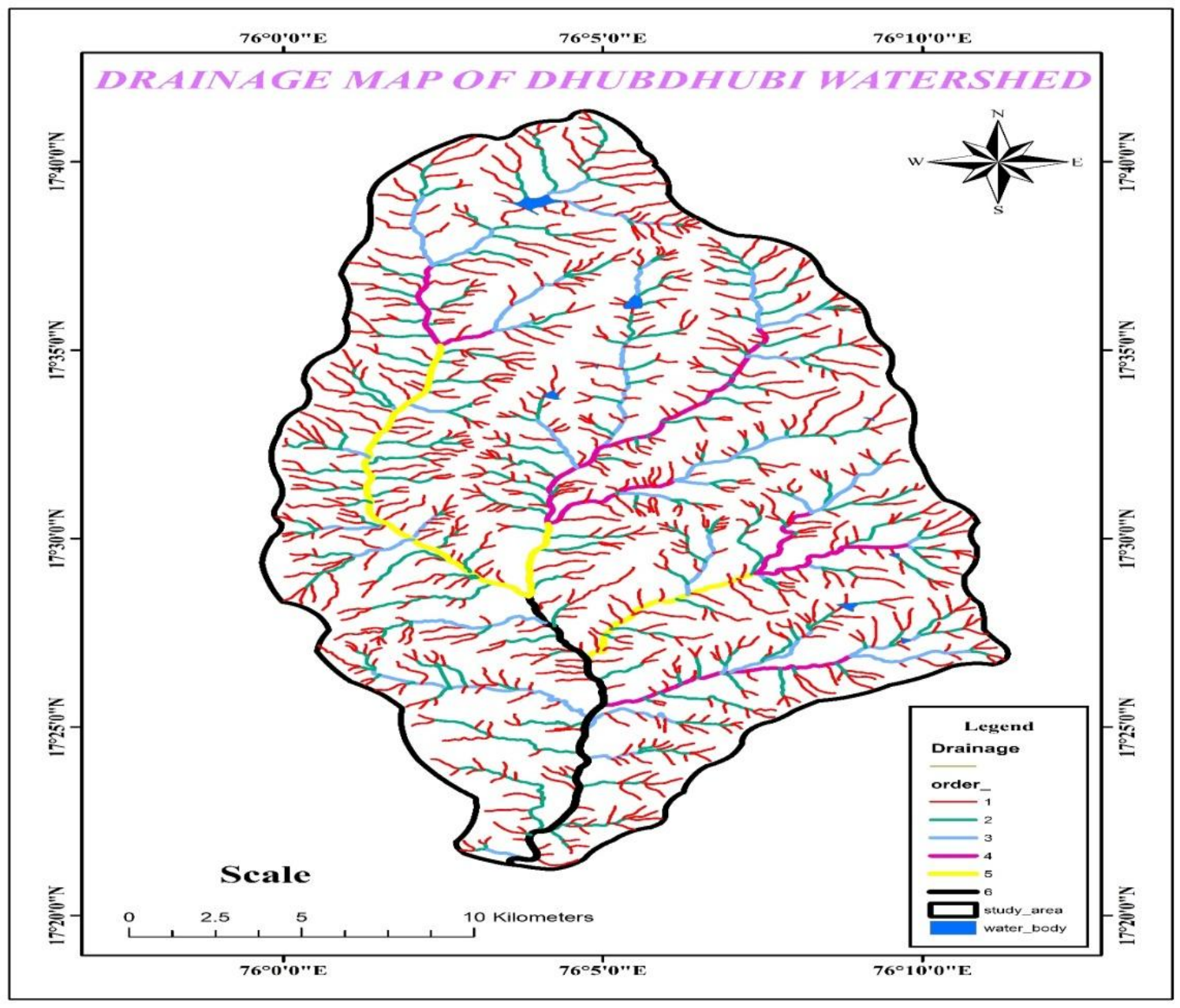

Fig: 2 Illustrates drainage map of the dhubdhubi basin 


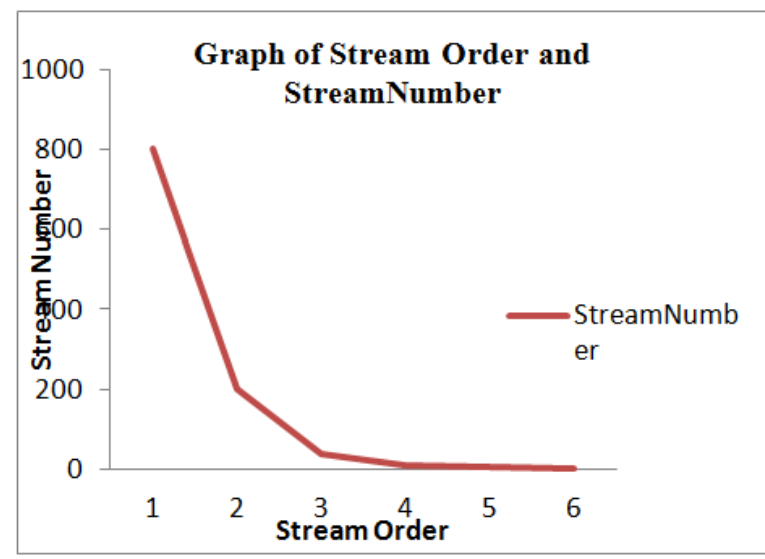

Fig no 3: Indicates graph of stream order and stream number

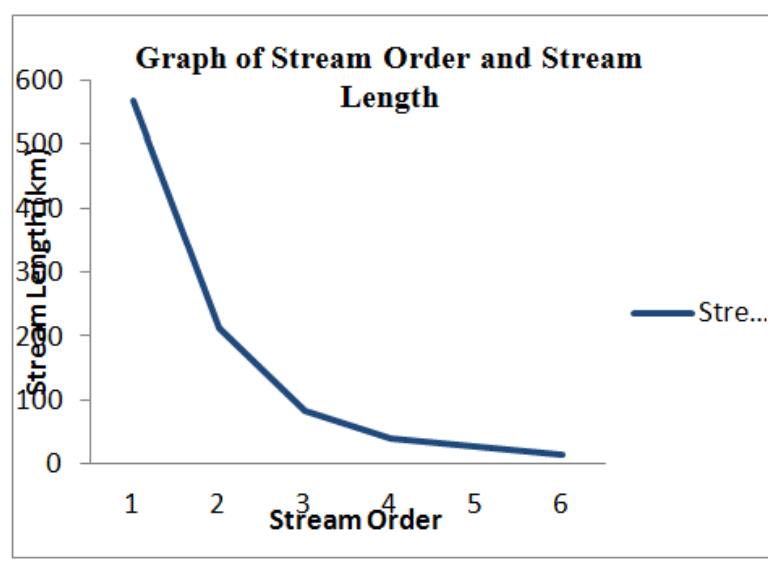

Fig no 4 : Indicates graph of stream order and stream length

Table no. 2: Shows Calculation of Linear aspects of the drainage basin.

\begin{tabular}{|c|c|c|c|c|c|c|c|c|c|c|}
\hline \multirow[t]{2}{*}{ Sub basin Name } & \multicolumn{5}{|c|}{ Mean Stream Length in Km ( Lsm ) } & \multicolumn{5}{|c|}{ Stream Length Ratio ( RI ) } \\
\hline & II & III & IV & \begin{tabular}{l|l} 
& $\mathrm{V}$ \\
\end{tabular} & VI & II / I & III / II & IV / III & $\mathrm{V} / \mathrm{IV}$ & $\mathrm{VI} / \mathrm{V}$ \\
\hline Dhubdhubi Basin & $0.701 .06 \quad 2.12$ & 5.65 & 671 & & & 2.65 & 2.09 & \multicolumn{2}{|l|}{1.69} & \\
\hline \multirow[t]{3}{*}{ Dhubdhubi Basin } & \multirow[t]{2}{*}{ Stream Order } & \multicolumn{6}{|c|}{ Bifurcation Ratio } & \multirow{2}{*}{\multicolumn{3}{|c|}{ Mean Bifurcation Ratio }} \\
\hline & & $\mathrm{I} / \mathrm{II}$ & II / I & & III / IV & $\mathrm{IV} / \mathrm{V}$ & V/VI & & & \\
\hline & & 4.015 & 5.12 & 5.57 & 2.3 & 3 & & 3.33 & & \\
\hline
\end{tabular}

Land Use / Land Cover Analysis: -

The Land Use and Land Cover map of the study area. The total areaunder study is $478.67 \mathrm{sqkm}$, contain total built up coverage at about $4.89342 \mathrm{sqkm}$. Highconcentration of settlement situated in Walsang and Karajgi which covers north\& West sideof the study area. The water bodies that are present in the study area are Dindur Lake, Achegaon Lake and Shirpanhalli Lake which covers area $3.57606 \mathrm{sqkm}$. Which is situated in North direction ofthe map and. Agricultural land occupies 146.258 sqkm,barren land occupies 269.965 sqkm. (Fig no-5)

\section{LULC MAP:-}

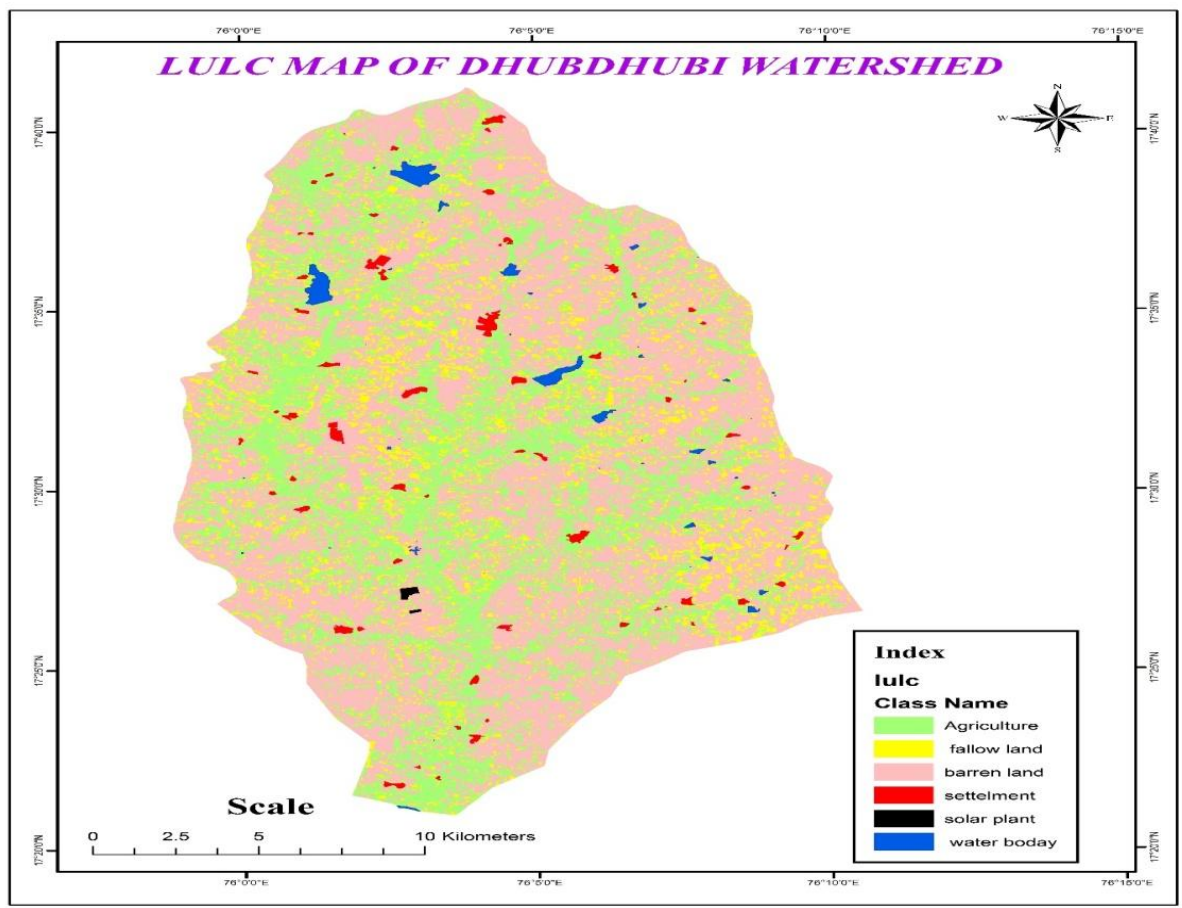

Fig no-5 : Illustrates LULC map of Dhubdhubi basin 


\section{Conclusion}

The study reveals that Toposheet data and GIS based approach in evaluation of drainage morphometric parameters and their influence on landforms, drainage characteristics at river basin level is more appropriate than the conventional methods. GIS based approach facilitates analysis of different morphometric parameters and to explore the relationship between the drainage morphometry and properties of landforms. The morphometric analyses were carried out through measurement of linear, of the watershed with morphometric parameters.

The morphometric analysis of the drainage network of watershed shows dendritic with moderate drainage texture. The difference in stream length ratio might bedue to change in slope and topography. The bifurcation ratio of the watershed indicates normal watershed category and the presence of moderate drainage density suggesting that ithas moderate permeable sub-soil, and coarse drainage texture. Value of stream frequency indicates that the watershed shows positive correlation with increasing stream population with respect to increasing drainage density. The value of form factor and circulator ration suggests that Dhudhubi watershed is less elongated. Hence, from the study it can be concluded that Cartosat (DEM) data, coupled with GIS techniques, prove to be a competent tool in morphometric analysis.

The drainage densities calculated for whole basin is 1.97 indicate that probability of branching. The bifurcation ratio varies between 2.33 to 5.57 . Generally high bifurcation ratios indicate geological and structural control. The variation of bifurcation ratio within the successive phase of drainage order could due to change irregularly and variation in a change of stream network and structural control of the basin.

GIS study allows reliable most accurate and most updated database on land resources. It has also been very useful in deriving geomorphometric parameters. In the present study GIS software are used to preparation of Base map, elevation map and base map of dhubdhubi basin.

\section{References}

[1]. A.B.Narayanpethkar, S.M.Sabale and V.R,Ghodake Department of Applied Geology, School of Earth Sciences, Solapur University, Solapur

[2]. Rafiq Ahmad Hajam, 2*Aadil Hamid, 2Naseer Ahmad Dar and 2Sami Ullah Bhat

[3]. Department of Geography and Regional Development, University of Kashmir-190006, Jammu and Kashmir

[4]. Ramu, B mahalingammorphometric analysis of tungabhadara drainage basin in Karnataka using geographical information system journal of engineering, Computers \& ApplieScience(JEC\&AS)

[5]. M. Rudraiah. S. Govindaiah . S. Srinivasvittala morphometric using remote sensing and GIS Techniques in the sub-basin of Ganga River Basin, Gulbarga distric, Karnata India.j.J.indiansoc. Remote Sens.(December 2008)36:351-360.

[6]. P.A.Pisal , A.S.Yadav,A.B.Chavan ,A.B.Chavanmorphometric analysis Of Bhogavati River basin ,Kolhapur District, Maharashtra, India. IOSR journals of Mechanical and civil Engineering (IOSR-JMCE)

[7]. M.A1 saud morphometric analysis of WadiAurnah Drainage System, Western Araiben Peninsula the open Hydrology Journal, 2009,3,1-10.

[8]. Nageswararao. K, SwarnaLatha, p, HariKrishna, M, morphometric Analysis of Gostani River basin in Andhra Pradesh State, India Using Spatial information Technology, INTERNATIONALJOURNAL OF GEOMATIC AND GEOSCIENCE OLUME1, NO 2,2010 .

[9]. Geena. G.B, Ballukraya.P.N. Morphometric Analysis of korattalaiyar River Basin, TamilNadu, India: AGIS approach. INTERNATIONAL JOURNAL OF EOMATIC AND GEOSCIENCE Volume 2, No2, 2011

[10]. P.T. Arvinda 1, H B Balkrishna. MARPHOMATRIC ANALYSIS OF VRISHABHAVATHI WATERSHADE USING REMOTE SENSING AND GIS IJRET : International Joournal of Research in Engineering and Technology.

IOSR Journal of Applied Geology and Geophysics (IOSR-JAGG) is UGC approved Journal with Sl. No. 5021, Journal no. 49115.

Unhale P L. "Geomorphological and Land Use / Land Cover Studies of Dhubdhubi Basin: District Solapur, Maharashtra"." IOSR Journal of Applied Geology and Geophysics (IOSR-JAGG) 5.4 (2017): 21-27 